First Peoples Child \& Family Review

A Journal on Innovation and Best Practices in Aboriginal Child Welfare Administration,

Research, Policy \& Practice

\title{
The Informal Caregivers of Aboriginal Seniors: Perspectives and Issues
}

\section{Sarah Parrack and Gillian M. Joseph}

Volume 3, Number 4, 2007

URI: https://id.erudit.org/iderudit/1069380ar

DOI: https://doi.org/10.7202/1069380ar

See table of contents

\section{Publisher(s)}

First Nations Child and Family Caring Society of Canada

\section{ISSN}

\section{8-489X (print)}

2293-6610 (digital)

Explore this journal

\section{Cite this article}

Parrack, S. \& Joseph, G. (2007). The Informal Caregivers of Aboriginal Seniors: Perspectives and Issues. First Peoples Child \& Family Review, 3(4), 106-113. https://doi.org/10.7202/1069380ar

\section{Article abstract}

Over 1 million Canadians aged 45-64 provide care to seniors with disabilities or physical limitations, and $70 \%$ are also employed - many full-time. Yet often policy assumes that all communities face the same eldercare challenges despite regional and cultural distinctions. This paper highlights what little is known about Aboriginal informal eldercare providers. Trends in health, employment and migration continue to raise concerns about the availability of caregivers, particularly in isolated communities. Difficulties accessing services increases the burdens of caregivers both locally and at a distance. More information about the context of Aboriginal eldercare is sorely needed.
This document is protected by copyright law. Use of the services of Érudit (including reproduction) is subject to its terms and conditions, which can be viewed online.

https://apropos.erudit.org/en/users/policy-on-use/ 


\title{
Thitest Peoples Choild \& sarovily Review
}

A Journal on Innovation and Best Practices in Aboriginal Child Welfare Administration, Research, Policy \& Practice

Volume 3, Number 4, 2007, pp. 106-113

\section{The Informal Caregivers of Aboriginal Seniors: Perspectives and Issues}

\author{
Sarah Parrack and Gillian M. Joseph ${ }^{\mathrm{b}}$
}

\begin{abstract}
a Sarah Parrack, Aboriginal Resource Centre, University of Guelph, sparrack@uoguelph.ca. Sarah has worked in the Aboriginal Resource Centre for the past two years and is actively involved in the development of co-curricular experiential learning opportunities for Aboriginal students. Currently she is developing a field course for Aboriginal students on Nunavut. She is also a fourth year student in Child, Youth and Family Studies at the University of Guelph. Over the last two years, in her role as Research Assistant at the Centre for Families, Work \& WellBeing, Sarah worked extensively on research projects related to the topics of combining employment and eldercare, as well as on projects associated with Aboriginal fathers and child welfare issues. She is a member of the Mississauga of the New Credit First Nation Band.
\end{abstract}

${ }^{b}$ Gillian Joseph, MSc. (FRHD Gerontology), Research Associate, Centre for Families, Work \& Well-Being, University of Guelph, gjoseph@uoguelph.ca. Gillian's academic career and research interests have been in the area of Gerontology, and more specifically around issues relating to aging and older workers. She is active in government and community funded projects as both principal investigator and co-investigator with a number of multi-disciplinary faculty from across Canada, and has authored and co-authored a number of articles and reports on topics directly related to aging, work and eldercare. Recently she partnered with Dr. Donna Lero (University of Guelph) to undertake a systematic review of the Canadian research on combining employment with informal eldercare, with Dr's Donna Lero, Norah Keating, Janet Fast and Linda Cook (University of Alberta) on a review of risks associated with negative outcomes among family caregivers and with Dr's. Belinda Leach and Susan Turner (University of Guelph) on a Status of Women Canada funded study of employed women's rural/urban migration as it affects providing informal care to seniors at a distance. As well as her research activities, Gillian also teaches a second year University of Guelph undergraduate course on adult development and aging.

Questions or correspondence concerning this article may be addressed to.

The Centre for Families, Work \& Well-Being

University of Guelph

17 University Ave. East

Guelph, Ontario, N1G 2W1

Phone: (519) 824-4120 (ext. 53714)

Fax: (519) 823-1388

Web: www.worklifecanada.ca

gjoseph@uoguelph.ca or sparrack@uoguelph.ca

\begin{abstract}
Over 1 million Canadians aged 45-64 provide care to seniors with disabilities or physical limitations, and $70 \%$ are also employed - many full-time. Yet often policy assumes that all communities face the same eldercare challenges despite regional and cultural distinctions. This paper highlights what little is known about Aboriginal informal eldercare providers. Trends in health, employment and migration continue to raise concerns about the availability of caregivers, particularly in isolated communities. Difficulties accessing services increases the burdens of caregivers both locally and at a distance. More information about the context of Aboriginal eldercare is sorely needed.
\end{abstract}

\section{Introduction}

It has been well documented that Canada's population is aging. Propelled by low fertility rates and longer life expectancy, the number of seniors aged 65 and older has increased by $68 \%$ over the last two decades (Turcotte \& Schellenberg, 2007). In a medium-growth scenario it is estimated that by 2056 seniors will represent over $27 \%$ of the total population (Statistics Canada, 2006). While government policy has begun to address some of the issues that older people and their families are facing with respect to policy shifts in healthcare, the economy and social support, the challenges associated with receiving and providing unpaid family care continues to be a concern.

Some 1.7 million Canadians aged 45-64 provide care to an elderly person with long-term disabilities or physical limitations, and 7 out of 10 of these caregivers are also employed - most of them full-time (Stobert \& Cranswick, 2004; Habtu \& Popovic, 2006; Lero \& Joseph, 2007). This is the current scope of the policy challenge and it is growing. Yet Keefe (1997) and others emphasize that national policies that are based upon the assumption that all communities face the same caregiving challenges fail 
to recognize important regional economic, social and cultural distinctions (Bedard, 2004; Sutherns, 2004). Inuit, Metis and First Nations seniors and their family caregivers know this all too well.

The fact that all Indigenous communities are not the same but are diverse in geography, language and social structure is important to emphasize. There are more than 50 individual languages belonging to 11 Aboriginal language families in Canada, reflecting a rich tapestry of distinctive history, culture, family and community identity, land and traditional knowledge (Norris, 2007). Therefore it is easy to see how the needs and solutions to problems may differ significantly between groups. Yet, this fact is often overlooked in policy development (Loppie, 2007).

Taken together, the three distinct groups of First Nations, Inuit and Metis make up approximately 1.3 million people (Statistics Canada, 2005b). Although Aboriginal populations tend to be younger than those in non-Aboriginal communities, there are nearly 40,000 Canadian Aboriginal people 65 years and older (Turcotte $\&$ Schellenberg, 2007). The number of these seniors is expected to rise significantly by 2017 , although it is predicted that each group (Inuit, Metis and First Nations) will experience different rates of growth (Statistics Canada, 2005b; Turcotte \& Schellenberg, 2007). This means that like non-Aboriginal people, the number of seniors in the Aboriginal population will represent a much higher percentage of their total population in less than 20 years (Lemchuck-Favel \& Jock, 2004).

For Aboriginal Canadians in general, and particularly for those who provide care to family members, housing shortages, high rates of unemployment and lack of access to health services are factors that affect both life expectancy and quality of life (Lafontaine, 2006). Given the distinctive cultural, linguistic, socio-economic and demographic characteristics of Canadian Aboriginal peoples then, it is not only likely that some aspects of the experience of aging in these communities will be unique compared to that of the non-Aboriginal majority, but also that the experience of being a family care provider to an Aboriginal senior will also be equally unique.

This paper brings together what little is known about family caregivers of Aboriginal seniors as a spark for discussions around aging, services and policy reform. While a few studies have explored issues associated with caring for seniors, and have included elderly Aboriginal Canadians with other seniors in their samples, very few studies have focused exclusively on the topic of caregivers and seniors in Aboriginal cultures. Building on a review of what is known about the context of Aboriginal seniors, this paper's main focus is on what is known about those who provide care to Aboriginal seniors. Teasing out what is buried within multi-cultural studies and re-framing this knowledge within a focused discussion on the caregivers of Aboriginal seniors provides practitioners with a more easily accessible resource upon which to build a case for change. Moreover, and importantly, it also assists in illuminating what is not yet known - exposing those gaps in understanding that if explored further might assist in the development of more appropriate policy interventions. In short, the paper addresses the following questions:

1. What is the context within which Aboriginal families provide care to seniors?

2. What are some of the challenges that caregivers of seniors in Aboriginal communities face?

3. What aspects of their experiences and needs are yet to be explored?

\section{Setting the Stage - The Context of Aging in Aboriginal Communities}

A discussion about the issues that impact upon family caregivers of Aboriginal seniors is incomplete without first considering the context of their care recipients. This is important because the health of the aging population, access that seniors have to services and supports, the information available to them and the resources that they choose to use or reject - and why - directly impacts upon the type, level and amount of care that seniors will need from their families and/or friends.

For most non-Aboriginal Canadians, the meaning of the word 'elder' and 'senior' is interchangeable and is defined by the dictionary as being "a person of advanced years" (Merriam-Webster, 2006). However, to be called an "Elder" in an Aboriginal community means much more than this. In many Aboriginal communities, age is not defined by chronology (Kramer, 1991). In fact, the concept of date-specific birthdays and life stage celebrations were only introduced there fairly recently in historical terms (Kramer, 1991). Not all elderly Aboriginal people are "Elders" and, in fact, not all "Elders" are elderly (Dumont-Smith, 2002). Nevertheless, it is important to emphasize the high esteem with which seniors are traditionally held in Aboriginal communities. It is particularly interesting to note that U.S. studies show that the role of elders in American Indian communities is possibly equated with lower incidences of self-destructive behaviours including alcoholism and suicide - which are not uncommon among some younger Aboriginal populations (Kramer, 1991).

Of the over 40,000 Aboriginal seniors in Canada, Ontario has the highest number of any province or territory (Statistics Canada, 2003). However, Manitoba and Saskatchewan have the largest proportion of 
Aboriginal seniors in their senior populations (Turcotte \& Schellenberg, 2007). Fifty-three percent of Canadian First Nation seniors lived on reserves in 2001, and of those that did not live on a reserve, most lived in rural as opposed to urban areas. In the far north, three-quarters of Inuit seniors live off reserve in largely isolated areas (Turcotte \& Schellenberg, 2007).

As is the case for the non-Aboriginal population, the Aboriginal senior population is disproportionately female (54\%) compared to their male counterparts $(46 \%)$. A notable exception is the Inuit population, where senior men outnumber women due to higher maternal mortality rates for this cohort (55\% men and $45 \%$ women) (Turcotte $\&$ Schellenberg, 2007). However, despite the fact that, in general, women live longer than men in most societies worldwide, the survival rate of Aboriginal women over 65 is significantly lower than the national average. In fact, Aboriginal women, who live on average to 76.6 years, have a life expectancy not only significantly lower than that of non-Aboriginal women (81 years) but even lower than that of non-Aboriginal men (77.2 years) (Health Canada, 2006; Statistics Canada, 2005a).

Chronic and longer term illnesses such as type II diabetes, HIV/AIDS, cardiovascular disease and arthritis are much more prevalent among the Aboriginal population (Indian and Northern Affairs Canada, 2007; Kuran, 2002). Furthermore, researchers speculate that chronic diseases in this population are often under-reported (Turcotte \& Schellenberg, 2007). Not only are these debilitating health problems more common for Aboriginal seniors as well, but they also tend to develop them at a much earlier age. A study of Aboriginal health revealed that one-third of First Nations and Labrador Inuit over 55 years of age had hearing problems, one-quarter had physical limitations that restricted them within their home, and one-eighth were unable to leave their residence and needed personal care in their home (Dumont-Smith, 2002; Curtis, 2007). Thus, a shorter life expectancy has led some to consider Aboriginal people to be "seniors" when they reach the age of 55, much younger than the comparable age of 65 for non-Aboriginal seniors (Dumont-Smith, 2002; O'Donnell, Almey, Lindsay, Fournier-Savard, Mihorean, Charmant, Taylor-Butts, Johnson, Pottie-Bunge \& Aston, 2005). In fact, many Canadian Aboriginal people do not live long enough to qualify for "senior" services - which suggests that, among other things, the eligibility criteria for seniors' programs needs to be re-evaluated (Kramer, 1991).

Researchers estimate that the poorer health status of Aboriginal seniors, coupled with the predicted growth in their numbers in the next few years, will have a disproportionate impact on the Canadian health system. Not only does this leave many Aboriginal seniors at risk of ill health, but the downloading of responsibility for care to families without the resources to support them also puts Aboriginal seniors at an increased risk for elder abuse (Lemchuk-Favel \& Jock, 2004; Dumont-Smith, 2002).

Since many of the chronic illnesses that are prevalent in Aboriginal communities are tied to poverty and isolation, it has been speculated that improving the socio-economic conditions of Aboriginal peoples might also improve their senior mortality rates. Cass (2004 in Curtis, 2007) points out that it is important to consider health disparities of First Nation peoples through a broader view of the social determinants of health in order to understand why the difference between Aboriginal and non-Aboriginal health often disappears once socio-economic status is accounted for.

The challenges that rural seniors in general face for access to services has been well documented. Keefe, Fancey, Keating Frederick, Eales and Dobbs (2004) note that in rural communities, and particularly communities with low density populations such as those in the far north where many Aboriginal seniors reside, economies of scale make it difficult to provide services like home care, nursing homes and acute care because those who need them are often spread out over a wide geographic area. Rural areas have proportionately fewer health care professionals, and services. Not only are distances to medical centres significant in some rural areas, but distances to grocery and drug stores, banks, post offices etc. may also be considerable. This impacts upon the ability of seniors to remain living independently. There are few places where Inuit seniors can access a doctor, and when they remain in their communities their families' resources are often stretched, particularly when they must leave isolated communities in order to obtain care.

Few First Nation and Inuit communities have longterm care facilities, which means that seniors who need nursing home care may need to move great distances away from family and friends (Lafontaine, 2006). Jock (as cited in Special Senate Committee on Aging, 2007) notes that there is only one nursing home bed for every 99 individuals in First Nations communities compared to one for every 22 individuals in the general population. Moreover, nursing homes for Aboriginal seniors are mainly located in Ontario and Manitoba, leaving seniors outside of those provinces without access. A better understanding of Aboriginal family care networks and comparisons of Aboriginal seniors who live in urban compared to rural and remote environments would certainly shed light on many of these issues.

Considering what has been noted above, it is perhaps no surprise that income levels among the Aboriginal population are significantly lower than for the nonAboriginal population, making it difficult both for seniors to live independently and for seniors and their caregivers 
to have the resources needed to gain access to privately purchased care (Buchignani \& Armstrong-Esther, 1999; Status of Women Canada, 2005). Aboriginal elderly are nearly twice as likely to be living with extended family members compared to non-Aboriginal seniors (DumontSmith, 2002), yet this could be more of an economic rather than a cultural issue per se. Some older Aboriginal people, particularly older women, have never engaged in the workforce and therefore do not have even basic CPP coverage. This significantly restricts the number of options available for housing, medical and social support, and puts a heavy financial burden on family caregivers (Special Senate Committee on Aging, 2007). U.S. research on American Indians shows that families with seniors in residence have three times the proportion of their population living in poverty compared to that of non-Aboriginal families (Kramer, 1991).

While Health Canada (1998) notes that, in general, a majority of Canadian seniors and their families feel uninformed about existing programs and services that may be available to them, given the significant diversity of languages, and the fact that over $12 \%$ of Aboriginal seniors speak neither English or French, information about programs and services is hard to communicate easily (Health Canada, 1998; Norris, 2007; Canadian Council on Learning, 2007). In isolated Aboriginal communities few people receive newspapers or magazines, and radio/television programs are only informative if they are broadcast in a language that can be understood (Health Canada 1998). Instead, seniors in these communities tend to depend upon a wide network of family and friends from whom they can obtain information or call for assistance.

\section{Family Caregivers of Aboriginal Seniors}

\section{a) Issues Associated with Gender and Work}

In most non-Aboriginal Canadian cultures, the care of the elderly often falls to the women in families. Census information tells us that Canadian caregivers in general are predominantly middle-aged women, who are employed full time, and who tend to be caring for more than one person - typically a parent (Fast \& Keating, 2001 ) in addition to their own children. Gender roles in Aboriginal households generally mirror those of the non-Aboriginal population and women are primarily responsible for housework, childcare, meal preparation, 'emotional work' and most of the care of older people (Buchignani \& Armstrong-Esther, 1999). A strong sense of family obligation is considered to be an integral part of Aboriginal culture, and women are expected to be the primary caregivers (Buchignani \& Armstrong-Esther 1999; Levesque, Trudeau, Bacon, Montpetit, Cheezo, Lamontagne \& Sioui Wawanoloath, 2001). Studies of
Metis women have found that their concept of health and wellness is often defined by their ability to care for family members (Bartlett, 2005).

Although Aboriginal women are expected to play a prominent role in family caregiving, unlike their nonAboriginal counterparts there appears to be little genderspecific difference in the percentages of those who report that they provide care to seniors. Approximately 24\% of Aboriginal women and $20 \%$ of Aboriginal men reported spending time caring for seniors in 2001 (Hull, 2006). The same holds true for providing intense caregiving, with $49 \%$ of Aboriginal men reporting that they provide more than 5 hours of care to seniors per week (considered high intensity) compared to $52 \%$ of Aboriginal women who report spending the same amount of time doing so (Hull, 2006).

Inuit women and Registered First Nation women on reserves are more likely than other Aboriginal groups to be caring for seniors, even though $72 \%$ of all Aboriginal women spend less than 10 hours per week caring for seniors (Hull, 2006). With a predominantly younger population and more children on average than their non-Aboriginal counterparts, 54\% of Aboriginal women also spend 30 hours or more per week caring for their children - which presumably impacts upon the time left for engaging in care for seniors (Hull, 2006). Given greater gender-specific differences in the type and intensity of care activities that are reported by the general population, more research on the gendered nature of care in Aboriginal families may help to tease out new and important insights on these differences.

Nevertheless, if Aboriginal women are expected to play a pivotal role in caring for the elderly, it is important to highlight a number of emerging trends and their implications in this regard. First, over half of Aboriginal women live off-reserve, in contrast to the higher proportion of Aboriginal seniors who live onreserve. Second, Aboriginal women, including middleaged women who are more likely to be providing care to seniors, have high migration rates, as seen between 1996 and 2001 when $36 \%$ of Aboriginal women between the ages of 45 to 64 changed residence (O'Donnell et al., 2005). This means that a significant number of Aboriginal women may need to provide care to elderly family members from a distance. Yet very little is known about how Aboriginal caregivers provide and manage care to seniors when they live far away.

Third, as Leipert \& Reutter (2005) note, the political environment of the Canadian north, where many Aboriginal communities can be found, is characterized by the undervaluing of both the region and of women themselves. As services decline in rural communities, the downloading of responsibilities for care of seniors 
from government to family members becomes more and more necessary, exploiting women in their role as care provider. Family caregivers are asked to undertake health care procedures that they are not necessarily qualified to perform (Joseph, Leach \& Turner, 2007). They become "sandwiched" by the sometimes competing demands of childcare and senior care. When Aboriginal caregivers are torn between their responsibilities for childcare and senior care, or torn between their responsibilities for work and family, life can become complicated and stressful. When caregivers must take time away from work in order to assist or care for seniors locally or at a distance, this can translate into higher levels of absenteeism which may lead to greater strains on employment and general caregiver well-being. Employment-related costs such as absenteeism, reduced hours, work-family conflict, having to quit work or turn down opportunities are evident in various studies of caregivers (Lero, Keating, Fast, Joseph $\&$ Cook, 2007), but few studies have explored the impact of these factors on the employed Aboriginal caregiver.

Although the unemployment rate of Aboriginal women is much higher than their non-Aboriginal counterparts, it is important to note that $50 \%$ of Aboriginal women aged 45 to 64 were in the labour force in 2001 (O’Donnell et al., 2005). The employment rate for Canadian women in general, and middle-aged women in particular, increased significantly over the past two decades, up from $44 \%$ in 1985 to $64 \%$ in 2005 for women aged 45 to 64 (Pyper, 2006). This may present employed Aboriginal and non-Aboriginal women caregivers with similar challenges. For example, approximately sixtypercent of Aboriginal women are employed in low-paying occupations in either sales, services, business, finance or administration (O’Donnell et al., 2005; Luffman \& Sussman, 2007). For Aboriginal and non-Aboriginal women who are employed in these occupations, few of these low-paying jobs would be likely to offer the flexibility for employees to arrange for care services during normal working hours, or to respond to care crises which are often unpredictable (Lero \& Joseph, 2007).

The fact that Aboriginal people tend to have lower incomes only exacerbates the problems that care providers in general report about the significant layout of financial resources associated with caring for seniors (Fast, Eales \& Keating, 2001). For all employed caregivers, but particularly for those who are forced to cut back working hours in order to provide care to family members, take lengthy unpaid leave, or find they have to leave the workforce to meet caregiving needs, it is well documented that the economic costs of caregiving can be significant, including the impact on caregiver pensions, benefits and economic independence that is not only short term but long term as well (Lero \& Joseph, 2007). It can also affect the opportunities for younger generations when resources for education must be diverted or sacrificed for caregiving. Yet these are circumstances that are often overlooked in policy development.

While caregivers who are proximate to their senior care recipients may be in a better position to engage in care management or to provide face-to-face care during lunch breaks or after work if needed, those who live in another city or in another time zone are at a significant disadvantage. In fact, the type of workplace that a caregiver works in, and the job she/he does, can cause significant problems for arranging long distance care by telephone. Employees who are tied to a desk with internet and a telephone may be more fortunate, while those working in retail, restaurants, services or on assembly lines are the least fortunate because they do not have access to communication resources, or flexible time during working hours to connect with agencies or other support people (Joseph, Leach \& Turner, 2007).

In addition to needing flexibility to access formal support mechanisms to assist them and their senior care recipients, Aboriginal care providers may also need ceremonial or spiritual support as well (Leipert \& Reutter, 2005). Yet for employed care providers these circumstances are not often foreseeable. The unpredictability of the course of illnesses that are more prevalent among Aboriginal seniors, and the length of the dying process, makes it difficult to plan for and to pace the management and hands-on provision of care to seniors (National Aboriginal Health Organization, 2002). Moreover, the fact that Aboriginal people are at higher risk for chronic illness has important implications not only for the care recipient, but also for care providers who may find themselves caring for a senior who has a chronic illness while suffering with the same chronic condition themselves.

Considering these points together, Aboriginal seniors may be facing a declining pool of family caregivers as the people most likely to provide care to them are increasingly facing their own health issues, leaving reserves and/or engaging in the workforce. Researchers note that existing studies on Aboriginal health have failed to adequately focus on the unique health needs of women (Young, 2003). How Aboriginal women and men provide care to seniors from a distance, or how they face the significant challenges associated with balancing the demands of work with the needs of family are important topics that need to be explored further.

\section{b) The Impact of Isolation}

Isolation is another factor in the lives of Aboriginal caregivers, including that at the individual and community levels. Individual isolation refers to the isolation that an individual experiences when seeking help, as in the 
case where cultural expectations and mores collide. For example, non-verbal communication such as personal space, or proxemics as it is called, is culturally defined (LeBaron, 2003). Aboriginal people tend not to use direct physical or eye contact when speaking to another person and it is often considered to be a sign of disrespect to look at someone directly. Unfortunately, this conflicts with the dominant Western cultural view that considers people who do not make eye contact as being rude or untrustworthy (Kramer, 1991). Many Aboriginal people find non-Aboriginal Canadians to be intolerably rude, overly forthright and loud (Kramer, 1991). Such cultural factors could pose a problem when Aboriginal seniors and their caregivers are seeking help and/or assistance from non-Aboriginal service providers. If service providers are uncomfortable and, in turn, make Aboriginal seniors or their caregivers feel uncomfortable about their behavior, it is less likely that a senior or caregiver in need will take part in a program or service, or will return for more information or assistance (Kramer, 1991).

Community isolation occurs for a number of reasons, but primarily when a community feels isolated due to lack of communication with the outside world and because of limited resources (Health Canada, 1998). Although community isolation is often associated with geographically remote, northern First Nation reserves, it is important to remember that this type of isolation can also be experienced by communities that are located in resource-scarce urban areas, as well as through racism and ethnocentricity.

Isolation can also occur when needs continually go unmet. Because of the nature of federal versus provincial government mandates in Canada, problems for care providers can occur when it is unclear as to who should be contacted or who is responsible for funding, maintaining or providing services and programs for Aboriginal seniors. Many services and policies for Aboriginal people are overseen by the federal government. However, the boundaries between provincial versus federal mandates can sometimes be very foggy. Fiddler (as cited in Special Senate Committee on Aging, 2007) notes that Metis are often caught between provincial and federal governments and tend not to have government services available to them despite their ethnic connection and culturallyspecific needs. Gaps can arise when there is confusion over which level of government should take responsibility to provide what aspect of services and Aboriginal seniors and their caregivers can fall through the cracks (Indian and Northern Affairs Canada, 2004).

Service delivery in remote communities can also consist of institutional discrimination leading to isolation when programs are absent or culturally inappropriate and thereby ineffective in meeting their goals (Ellerby,
McKenzie, McKay, Gariepy and Kaufert, 2000). This can include factors such as the space needed for privacy and comfort in the delivery of patient care, which for Aboriginal seniors could happen when the only hospital bed available is in a family's living room, or when lack of access to a wheelchair - or the space available in a dwelling to use it - limits mobility (National Aboriginal Health Organization (NAHO), 2002). In Metis culture, health and well-being exists as a collective concept, yet most programs are oriented toward a more individualistic approach (Bartlett, 2005). Therefore, resources that are initiated without a thorough understanding of culture and context can, unintentionally, create institutional and social barriers that may prevent access, and may perhaps even doom programs to unnecessary failure.

\section{Conclusion}

The context within which Aboriginal families provide care to seniors is a challenging one. Of the 1.3 million Aboriginal peoples in Canada, approximately 40,000 are aged 65 and older. Although primarily a younger population compared to non-Aboriginal people, the rapidly increasing number of Aboriginal seniors will have important implications for Canada's economic, social and political agendas in the next decade.

It has been suggested that like women in most European cultures, women in Aboriginal communities are encouraged to take on the role of care provider for family members. However, trends in Aboriginal women's health, employment, migration and economic security will continue to raise concerns about who is available to provide care to the elderly, particularly in rural and remote communities.

The low life expectancy of Aboriginal seniors, generally poor health, low incomes and difficulties accessing formal services and supports increases the financial and psychological burden of those who must assume the responsibility of care to seniors, both locally and from a distance. Those who must balance the demands of care to seniors with childcare, with the added dimension of employment, may be at significantly greater risk.

Programs that fail to take into consideration the unique and diverse cultural mores and traditions of Aboriginal people will result in institutional discrimination, rendering programs that may be ineffective in their goals to support Aboriginal seniors and their caregivers. Yet few studies evaluate programs using an Aboriginal cultural lens.

Information about gender differences, long distance care and work-life balance have been teased out for other populations but are scarce in the Aboriginal context. The 
impact of individual and community isolation, along with institutional discrimination and ethnocentric assumptions about seniors and their caregivers, are important topics that need to be more fully explored. As the number of seniors continues to rise, it is important to reflect on the fact that it is estimated that unpaid family caregiving has a replacement value that saves Canadian taxpayers over 5 billion dollars annually (Fast \& Frederick, 1999). The impact of caregiving can affect caregivers not only into the longer term, but it also can ripple to affect future generations. It is therefore important to explore trends across Aboriginal cultures and to highlight the challenges associated with providing care to Aboriginal seniors. Qualitative studies that give voice to caregivers would provide important insights into this experience. Only this way will there be a fuller understanding of what supports are needed, and what innovative solutions can be appropriately facilitated to improve the lives of those who provide care. Without this information, we stand in danger of failing to address the issues relevant not only to those who care for Aboriginal seniors, but to all older Canadians and their care providers, as their numbers continue to rise.

\section{References}

Bartlett, J. (2005). Health and well-being for Métis women in Manitoba. Canadian Journal of Public Health, 96(1), 22-27.

Bedard, M., Koivurania, A. and Stuckey, A. (2004). Health impact on caregivers of providing informal care to a cognitively impaired older adult: rural versus urban settings. Canadian Journal of Rural Medicine, 9: 15-23.

Buchignani, N. and Armstrong-Esther, C. (1999). Informal care and older Native Canadians. Aging and Society, 19: 3-32.

Canadian Council on Learning. ( 2007). The Obstacles to Learning about Caring for Elders in Canada. July 12, 2007. Retrieved from http://www.ccl-cca.ca/CCL/Reports/ LessonsInLearning/LinL20070700_Learning_About Elder Care.htm.

Curtis, L.J. (2007). Health Status of On and Off-reserve Aboriginal Peoples: Analysis of the Aboriginal Peoples Survey. Social and Economic Dimensions of an Aging Population. SEDAP Research Paper No. 191. Retrieved from http://socserv2.socsci.mcmaster.ca/ sedap/p/ sedap191.pdf.

Dumont-Smith, C. (2002). Aboriginal Elder Abuse in Canada. Aboriginal Healing Foundation. Retrieved from http://www. ahf.ca/pages/download/28 37.

Ellerby, J. H., McKenzie, J., McKay, S, Gariepy, G.J. and Kaufert, J.M. (2000). Bioethics for clinicians: Aboriginal cultures. Canadian Medical Association, 163(7).

Fast, J. and Frederick, J.A. (1999). Informal Caregiving: Is it Really Cheaper? International Assoc. of Time Use Researchers. Colchester, England.
Fast, J., Eales, J. and Keating, K. (2001). Economic Impact of Health, Income Security and Labour Policies on Informal Caregivers of Frail Seniors. Ottawa, Status of Women Canada.

Fast, J. and Keating, N. (2001). Informal Caregivers in Canada: A Snapshot. Edmonton: Health Services Division, Health Policy and Communications Branch, Health Canada.

Habtu, R. and Popovic, A. (2006). Informal Caregivers Balancing Work and Life Responsibilities. Policy Research Initiatives, Canada - Policy Research Initiative.

Health Canada. (1998). Reaching Out: A Guide to Communicating with Aboriginal Seniors (Cat. No. H88-3/20-1998E). Ottawa, ON: Minister of Public Works and Government Services. Retrieved from http://www.phacaspc.gc.ca/seniors-aines/pubs/communicating_aboriginal/ pdf/reachingout_e.pdf.

Health Canada (2006). First Nation and Inuit Health: Statistical Profile on Health of First Nations in Canada. Retrieved from http://www,hc-sc.gc. ca/fnih-spni/pubs/gen/stats profil_e.html.

Hull, J. (2006). Aboriginal Women: A Profile from the 2001 Census. Retrieved Aug 16, 2006, from http://www.aincinac.gc.ca/pr/pub/abw/index_e.html.

Indian and Northern Affairs Canada (INAC). (2004). Assisted Living Program: National Manual (Cat No. H39560/2000E). Ottawa, ON: Minister of Public Works and Government Services Canada. Available at: http://www. ainc-inac.gc.ca/ps/mnl/alp/alp_e.pdf.

Indian and Northern Affairs Canada (INAC) (2007). Fact Sheet on Aboriginal Health. Retrieved from http://www.ainc-inac. gc.ca/pr/info/fnsocec/abhl_e.html.

Joseph, G., B. Leach and S. Turner (2007). Caring at a Distance: Working Women, Rural to Urban Migration and the Compassionate Care Challenge. Ottawa, Status of Women Canada.

Keefe, J. M. (1997). The likelihood of combining employment and helping elderly kin in rural and urban areas among Canadian regions. Canadian Journal of Regional Science, Fall 97. Retrieved from http://www.lib.unb.ca/Texts/CJRS/ bin/get.cgi?directory $=$ Fall97/keefe $/ \&$ filename=Keefe.htm.

Keefe, J., P. Fancey, N. Keating, J. Frederick, J. Eales and B. Dobbs (2004). Caring Contexts of Rural Seniors: Phase I Technical Report. Ottawa: Statistics Canada, Veterans Affairs Canada, Royal Canadian Legion.

Kramer, B.J. (1991). Urban American Indian aging. Journal of Cross-cultural Gerontology, 6:205-217. Retrieved from http://www.springerlink.com/content/g7433p3242240w72/.

Kuran, H.J. (2002). The Barriers to Healthy Living and Movement for Frail Aboriginal Elders. National Indian \& Inuit Community Health Representatives Organization (NIICHRO). Retrieved from http://www.niichro. com/cfc/cfc_3.html.

Lafontaine, C. (2006). Presentation to the Senate Standing Committee on Aging. National Aboriginal Health 
Organization, Monday, November 27, 2006. Retrieved from http://www.naho.ca/publications/agingPresentation.pdf.

LeBaron, M. (2003). Cross-cultural Communication. Beyond Intractability. Retrieved Aug 16, 2006, from http://www.beyondintractability. org/essay/cross-cultural_communication/.

Leipert, B. \& Reutter, L. (2005). Developing resilience: How women maintain their health in northern geographically isolated settings. Qualitative Health Research, 15(1): 49-65.

Lemchuck-Favel, L. and Jock, R. (2004). Aboriginal Health Systems in Canada: Nine Case Studies. Journal of Aboriginal Health: 1(1).

Lero, D.S., Keating, N., Fast, J. Joseph, G. and Cook, L. (2007). The Interplay of Risk Factors Associated with Negative Outcomes among Family Caregivers: A Synthesis of the Literature. Report for Human Resources and Social Development Canada.

Lero, D.S. and Joseph, G. (2007). A Systematic Review of the Literature on Combining Work and Eldercare in Canada. Final Report for Homewood Health. Retrieved from http://www.worklifecanada.ca.

Levesque, C., Trudeau, N. Bacon, J., Montpetit, C., Cheezo, M., Lamontagne, M. and Sioui, C. Wawanoloath (2001). Aboriginal Women and Jobs: Challenges and Issues for Employability Programs in Quebec. Ottawa: Policy Research Fund, Status of Women Canada.

Loppie, C. (2007). Learning from the grandmothers: Incorporating Indigenous principles into qualitative research. Qualitative Health Research, 17 (2): 276-284.

Luffman, J. and Sussman, D. (2007). The Aboriginal labour force in western Canada. Perspectives on Labour and Income, 8(1), January. Ottawa: Statistics Canada. www. statcan.ca/english/freepub/75-001-XIE/10107/art-2.htm.

Merriam-Webster Online. (2006). Retrieved Aug 16, 2006, from http://www.m-w.com/.

National Aboriginal Health Organization (NAHO) (2002). Discussion Paper on End of Life/Palliative Care for Aboriginal Peoples. Retrievd from http://www.naho. ca/english/pdf/re briefs2.pdf.

Norris, M.J. (2007). Aboriginal languages in Canada: emerging trends and perspectives on second language acquisition. Canadian Social Trends (83):20-28. Ottawa: Statistics Canada.

O’Donnell, V., Almey, M., Lindsay, C., Fournier-Savard, P., Mihorean, K., Charmant, M., Taylor-Butts, A., Johnson, S., Pottie-Bunge, V., and Aston C. (2005). Women in Canada: A Gender-based Statistical Report. Ottawa: Statistics Canada. Retrieved from http://www.statcan. $\mathrm{ca} /$ bsolc/english $/$ bsolc? catno $=89-503-X$.

Pyper, W. (2006). Balancing career and care. Perspectives on Labour and Income (November, 2006).
Special Senate Committee on Aging. (2007). Proceedings of the Special Senate Committee on Aging. Issue 8 -Evidence. Ottawa. Retrieved from http://www.parl.gc.ca/39/1/parlbus/ commbus/senate/com-e/agei-e/08ev-e.htm?Language $=\mathrm{E} \& \mathrm{P}$ $\underline{\operatorname{arl}=39 \& \text { Ses }=1 \& \text { comm id }=600}$.

Statistics Canada (2006). Canada's population by age and sex. The Daily. October 26, 2004. Ottawa: Statistics Canada. Retrieved from http://www.statcan.ca/Daily/ English/061026/d061026b.htm.

Statistic Canada. (2005a). Health Reports (Catalogue no. 82003-XPE). Ottawa:Ministry of Industry.

Statistics Canada. (2005b). Projections of the Aboriginal populations, Canada, provinces and territories (Cat No. 91-547-XIE). Ottawa: ON: Minister of Industry. Retrieved from http://courseweb.edteched.uottawa.ca/Medicine Health/data/Images/Aboriginal\%20population\%20projecti ons.pdf.

Statistics Canada (2003). Aboriginal peoples of Canada: A demographic profile (Catalogue No. (6F0030XIE200107). Ottawa: ON: Minister of Industry. Available at: http:// www12.statcan.ca/english/census $01 /$ products/analytic/ companion/abor/pdf/96F0030XIE2001007.pdf.

Status of Women Canada (2005). Assessing Gender Equality Trends in the Situation of Women and Men in Canada. Ottawa: Status of Women Canada. Retrieved from http://www.swc-cfc. gc.ca/resources/consultations/ges09-2005/assessing_e.pdf.

Stiegelbauer, S. M. (1996). What is an Elder? What does an Elder do? First Nation Elders as teachers in culture-based urban organization. The Canadian Journal of Native Studies. 1, 37-66.

Stobert, S. and K. Cranswick. (2004). Looking after seniors: Who does what for whom? Canadian Social Trends. No. 74. Statistics Canada Catalogue no. 11-008-XIE. P. 2-6. Retrieved from http://www.statcan.ca/english/freepub/11008=XIE/0020411-008-XIE.pdf.

Sutherns, S. and Fish, S. (2003). Sutherns, R. (2004). Understanding rural and remote women's health in Canada. In, Sutherns, R., McPhedran, M. \& Haworth-Brockman. M. (eds.), Rural, remote and northern women's health: Policy and research directions: Summary report. Winnipeg: PWHCE.

Turcotte, M. and G. Schellenberg (2007). A Portrait of Seniors in Canada. Ottawa: Statistics Canada. Retrieved from http://www.statcan.ca/english/freepub/89-519-XIE/89-519XIE2006001.pdf.

Young, T. (2003). Review of research on aboriginal populations in Canada: Relevance to their health needs. British Medical Journal, 327, 419-422. 